\title{
LA DANZA COMO TRANSMISOR PUBLICITARIO A TRAVÉS DE LAS EMOCIONES.
}

The dance as advertising transmitter through emotions

\author{
Ángela María Bermúdez Muñoz \\ anbermudez11@poligran.edu.co \\ Katherine Rozo Cuadros \\ krocuadr@poligran.edu.co \\ Politécnico Grancolombiano Institución Universitaria \\ Mercadeo y Publicidad/Psicología \\ Colombia
}

Resumen

La danza es una de las disciplinas del arte, que permite comunicar por medio del cuerpo; su lenguaje no verbal se basa en la expresión de emociones y sentimientos a través de movimientos al compás o ritmo de la música, esta mezcla se une a otras disciplinas del conocimiento, para articularse y evidenciar comportamientos humanos, como la neurociencia, la biología, fisiología, antropología que hacen parte del estudio corporal y neurológico del cuerpo, pero que a su vez permite articular otras áreas del conocimiento como es el caso de la publicidad, donde según Thompson (2005) "es considerada como una de las más poderosas herramientas de la mercadotecnia, específicamente de la promoción, por las organizaciones para dar a conocer un determinado mensaje relacionado con sus productos, servicios, ideas, a su grupo objetivo". En el caso de la danza articulada con la publicidad se emplean las emociones como el puente de comunicación del mensaje. Es por ello por lo que este artículo explora de manera conceptual los conocimientos sobre los procesos básicos del sistema nervioso, comprendiendo el funcionamiento de los procesos neuronales y psicológicos tanto de la danza como de la publicidad se entiende como una involucra la otra a través de los anuncios publicitarios como comerciales en los que se involucra dichas disciplinas.

Palabras clave:

Publicidad, danza, cognición, emoción. 


\section{INTRODUCCIÓN}

El presente trabajo tiene como fin realizar una revisión bibliográfica, con el objetivo de entender y visualizar cómo el arte de la danza se ve involucrada con el mundo de la publicidad y así mismo la capacidad de transmitir emociones a sus consumidores, los cuales permiten que cada vez se formen nuevas ideas de innovación que a su vez permita que esta parte del arte siga creciendo e incentivando a grandes y pequeños a ser parte de ella (Daza-Orozco, 2019).

Hablando con brevedad, la danza ha sido parte esencial en la vida del ser humano, por medio de ella nuestros antepasados se reunían para realizar bailes y rituales de agradecimiento o celebraciones, que con el pasar del tiempo fueron evolucionando a medida que el hombre se esparcía alrededor del mundo y consigo creaba su propia cultura.

Poco a poco la danza fue tomando fuerza y dejo de ser solo un ritual, para transformarse en un lenguaje no verbal; el cual permite transmitir mensajes emocionales por medio del cuerpo y la música, para De las Salas (2015) "La educación corporal involucra un acervo de saberes, conocimientos y prácticas relacionadas con las acciones motoras de los seres humanos que, al impregnársele una intensidad formativa, determina no solo el tipo de actividad corporal vivenciada, sino la calidad de las mismas, a partir de las producciones motoras que el niño, joven o adulto entabla en una relación integral en la que la mente y el cuerpo son considerados como una unidad que se complementa".

Como se expuso anteriormente la danza permitió dar grandes pasos para la construcción de conocimientos que no tuvieran un solo fin en el estudio de lo biológico, sino también en lo corpóreo; que conlleva a analizar cómo a través del movimiento se observa no solo coordinación o ritmo sino lo que se puede traspasar al otro.

\section{Justificación:}

La danza y el hombre fueron evolucionando de manera progresiva, y a través de todos estos cambios la danza dejo de ser algo más que un ritual de agradecimiento o de celebración, y poco a poco se fue transformando en un lenguaje no verbal; el cual es capaz de transmitir emociones y sentimientos como la alegría, la tristeza, el enojo, el amor entre otros. Citando a Padilla (s.f), quien afirma que "las emociones condicionan nuestra conducta, nuestra salud y nuestro pensamiento; si queremos entender algo de sí mismos y de los otros, lo que se trata es de tomar en consideración las emociones, tenerlas en cuenta, y no ignorarlas o rechazarlas como si fueran elementos externos perturbadores. Esta idea, que empieza a coger fuerza a partir de los descubrimientos de Charles Darwin, William James y Sigmund Freud, deja atrás la posición errónea según la cual las emociones son un estorbo para la inteligencia y la racionalidad." p. 425. Siguiendo con el planteamiento del autor sobre las emociones se ha concretado por medio de diversos estudios realizados se ha concretado que las emociones cumplen con nuestra supervivencia y nos permiten interactuar en el mundo en que que vivimos.

Algunos de los autores que aportaron con las investigaciones, fueron los mencionados al principio del texto que a su vez contribuyeron a grandes teorías como la psicología funcional de (William James), la teoría de la evolución de (Darwin), y la teoría psicoanalítica de (Freud), que ayudaron a entender la importancia de las emociones en la vida del ser humano. Las emociones vienen dadas gracias al órgano más importante del cuerpo humano, ya que a través de él se regula y coordina toda actividad interna del cuerpo al tiempo de responder a los estímulos externos del ambiente los cuales van a generar una respuesta o comportamiento, esta breve descripción alude al encéfalo, es importante aclarar que esto sucede en la mayor parte de[ABm1] los animales, es aquí donde el mercadeo y la publicidad centran su atención puesto que, como lo describen De Balanzó, C., \& Sabaté, J. (2007). En su artículo de las neurociencias y publicidad: la nueva frontera de la persuasión, donde describen que "el neuromarketing ha cobrado un inusitado interés entre muchos expertos en marketing y publicidad. Se presenta como una nueva frontera por conquistar por parte de estas disciplinas, porque, en su estadio experimental está siendo una herramienta válida para demostrar, para hacer tangible, la relación emocional que se establece entre las marcas y los consumidores”. p. (909). Con esto los autores plantean los avances que se han venido fortaleciendo en el mundo del mercadeo y la publicidad y como constatan el grado de interés no solo por los productos sino también por los servicios que ofrece la industria. 
Objetivo

Realizar una revisión bibliográfica partiendo de bases académicas para analizar acerca de cómo la danza es transmisora publicitaria a través de las emociones, esclareciendo conceptos fundamentales a partir de teorías expuestas por diferentes autores que aportaron a la construcción desde las diversas disciplinas del conocimiento.

Danza

Emociones en la danza

Semiótica de la danza

\section{Método}

Esta investigación se da desde la articulación entre los programas de Psicología, Mercadeo y Publicidad. Su inquietud surge a partir de los estudios previos del Semillero de investigación SomaLab que explora la aplicación de las Artes Escénicas en el Marketing de Experiencias. Su alcance exploratorio y sugiere un estado del arte donde se disponen conceptos para lograr evidenciar la articulación de los temas entre sí.

\section{Resultados}

A lo largo de la historia la danza ha tenido personajes que han venido construyendo a grandes pautas de conocimiento no solo en lo teórico sino también en lo práctico, un concepto que hay que destacar son las técnicas corporales, ya que, como lo menciona Mora, A. S. (2011). Y Mauss define a las técnicas corporales como "la forma en que los hombres, sociedad por sociedad, hacen uso de su cuerpo en una forma tradicional, aquí el aprendizaje es dónde principalmente el espacio cultural de las técnicas corporales: son actos eficaces tradicionales que se realiza como si fueran actos mecánicos o físicos, pero tienen sentido sólo dentro de un sistema simbólico particular. Que a su vez conecta con las emociones que hacen parte de la mayoría de seres vivos", partiendo de la afirmación demora y Mauss ayuda a dar una mirada y recalcar la importancia del contexto y cultura en la cual se desarrolla los movimientos corpóreos, debido a que al generar una o varias emociones, también conllevan a surgir significados que solo serán entendidos por las personas que conforman la cultura en específico(Daza-Orozco, CE \& Cera-Ochoa, 2018; Daza-Orozco, CE, 2018).

Por otro lado, Mosterín, J. (2003). Afirma que, la cultura es la información que se transmite entre cerebros, es decir, la información transmitida por aprendizaje social. Esto a su vez hace que se cree un gran interés investigativo y riguroso, para entender el significado de la cultura, de ese circuito de movimientos que permiten comprender o traducir ese lenguaje que se hace llamar danza, qué emociones transmite y en qué contextos de la vida son simbólicos, puesto que no solo se trata de estudiar la cultura y quienes la conforman, sino que además busca los métodos y formas de leer el ambiente en el que se dan.

Según Ávila, R. (2011) “Una nueva actitud, más amable y respetuosa con las razones del corazón, ha ido ganando terreno durante el siglo XX y ha adquirido un especial impulso en la actualidad, extendiéndose a los ámbitos de la educación, las ciencias de la comunicación, la política, la sociología, la medicina, la literatura; y también, a las artes en general, y muy especialmente, a las llamadas artes performativas". Lo cual quiere decir que tanto a finales del siglo XX e inicios de siglo XXI las emociones no sólo pasan a ser consideradas fundamentales para entender el comportamiento humano, sino que, además, se ponen de moda. Ávila, R. (2011). Debido a esto las campañas publicitarias e institucionales, compuestas principalmente por el público potencial de las artes como: el teatro, la música y la danza de países más desarrollados, frecuentan una y otra vez a lemas que giran alrededor de las emociones como por ejemplo "vivir la fuerza de las emociones".

Pero para entender cómo se enlazan las emociones en el mundo de la danza, primero se debe constatar qué se entiende por emociones, ya que, este tema viene desde varios siglos atrás y uno de los autores que planteo el tema de las emociones fue Descartes, quien partió con el tema de las pasiones y da un breve significado lo que para entonces se entendía el concepto de emoción, como lo menciona Ávila (2011) “(Descartes, 1994: 82). Define las emociones como afecciones pasivas causadas al alma por el movimiento de los espíritus vitales; siendo la glándula pineal (situada en medio del cerebro) la que desempeña un papel determinante en su desarrollo. 
Esto quiere decir que «un movimiento particular en esta glándula, que la naturaleza ha establecido para hacer que el alma sienta esta pasión. Y para relacionarse estos poros principalmente con los pequeños nervios que sirven para reducir o ampliar los orificios del corazón, ocurre que el alma siente la pasión principalmente como si fuera en el corazón»", con esta afirmación el autor muestra por medio de una revisión histórica más detallada como el cerebro, juega un papel fundamental en la sincronización de movimientos, inteligencias como la cinestésica, formas de aprendizaje, etc.

Hay que mencionar además que, para Mosterín, J. (2003). Y según Descartes, “la glándula pineal o epífisis es una glándula endocrina periforme, del tamaño de un guisante, situada en medio del encéfalo, detrás del tálamo y encima de los tubérculos cuadrigéminos superiores, y que forma parte del diencéfalo o cerebro intermedio". Dada la ubicación de la glándula pineal se puede entender la importancia de esta dentro de los procesos del SN y cuerpo humano, ya que la glándula pineal es la que se encarga de segregar una hormona llamada melatonina y por medio de ella se dan los estados de vigilia y sueño, permitiendo la regulación del reloj biológico y las actividades que se realizan día a día.

Por otro lado, para Bosch, M. J. (2009). "En los últimos veinte años, las neurociencias y las ciencias sociales han descubierto el papel fundamental de las emociones en el bienestar y la felicidad de las personas (Fernández-Berrocal 2009 33). El autor mencionado avala que un buen conocimiento y manejo emocional repercute positivamente sobre la salud". Las emociones establecen y determinan decisivamente nuestro modo de percibir el mundo, nuestros comportamientos y algo muy importante como la toma de decisiones.

Bosch, M. J. Habla de habilidades emocionales, las cuales derivan una serie de procesos que nos ayudan a reconocer, comprender qué siento y lo que sienten los demás, y a controlar cómo me siento. Se encuentran principalmente tres procesos:

a. La Percepción emocional: Consiste en reconocer conscientemente nuestras emociones e identificar qué sentimos y ser capaces de darle una etiqueta verbal.

b. La Comprensión emocional: Requiere integrar lo que sentimos en nuestro pensamiento y saber considerar la complejidad de los cambios emocionales.

c. La Regulación emocional: Consistente en dirigir y manejar las emociones tanto positivas como negativas de forma eficaz. (Fernández-Berrocal y Ramos-Díaz 2005a 20).

La regulación conduce a una estabilidad emocional y un estado anímico óptimo, adecuado a la situación, que permita regular supone valorar prioridades, elaborar y generar pensamientos adaptativos que controlen las emociones. Bosch, M. J. (2009).

Tanto para ejercer un movimiento, técnica de la danza o expresar una emoción en la misma u otra situación de nuestras vidas, estas pasan por un proceso dado principalmente en el cerebro; algunos de los descubrimientos de la neurociencia actual pueden ayudar a mejorar significativamente algunos aspectos fundamentales de la educación artística.

Diferentes autores definen conceptos de psicomotricidad de como "una función del ser humano que sintetiza psiquismo y motricidad con el fin de permitir al individuo adaptarse de manera flexible y armoniosa al medio que le rodea. Puede ser entendida como una mirada globalizadora que percibe las interacciones tanto entre la motricidad y el psiquismo como entre el individuo global y el mundo exterior. Puede ser entendida como una técnica cuya organización de actividades permite a la persona conocer de manera concreta su ser y su entorno inmediato para actuar de manera adaptada. (Lièvre y Staes, 1992)" citado por Megías Cuenca, M. I. (2009).

Lo descrito anteriormente permite dar una interpretación sobre como un movimiento o montaje coreográfico se vuelve en algo más complejo, que una puesta en escena o un servicio que se quiera adquirir o vender, debido a que es más complejo de lo que se percibe, para ello se necesita tratar de comprender los procesos que se dan desde lo neurológico hasta la publicidad.

Sin embargo, existen distintos mecanismos que nos ayudan a entender los procesos que se dan a nivel neuronal como es el caso de las neuronas espejo. La investigación sobre las llamadas células o neuronas espejo pone de manifiesto que aprendemos viendo (o sintiendo) acciones que hacen otras personas sin que haya que realizarlas necesariamente de una manera física, cabe señalar que las neuronas espejo permiten la 
empatía con el otro, es decir que se genere una conexión el cual permite leer en un lenguaje más corpóreo que verbal, lo que otro quiera transmitir.

Una de las formas de transmitir emociones, procesos de aprendizaje, inteligencia cinestésica y demás es por medio de la Biodanza, la cual genera según, Padilla, G. A. S. (s.f), "mediante los ejercicios y danzas, campos específicos muy concentrados para estimular los potenciales genéticos. Una sesión de Biodanza es un bombardeo de ecofactores positivos sobre la función integradora-adaptativa-límbico-hipotalámica." p. 6.

Existen múltiples tipos de danza, ritmos, escenografías, movimientos, destrezas, habilidades, contextos y sobre todo personas, que se inclinan por el mundo del arte para generar un impacto tanto externo como interno, entiéndase externo a la cultura a la cual pertenezca e interno a los procesos motivacionales, emocionales y las conexiones a nivel neuronal que ocurren en todo el cuerpo para que se disipen los complejos pero necesarios procesos de movimiento, ritmo, lenguaje, entre otros, que a su vez generan una activación de diferentes zonas del SN, el cual será descrito más adelantev (Norman-Acevedo, 2018).

Bases neuropsicológicas del movimiento:

Como se ha mencionado en repetidas ocasiones las neurociencias juegan un papel primordial en cualquier tema de investigación; en este apartado se pretende entender qué partes del sistema nervioso están encargados de ejecutar la acción de movimiento y que zonas del cerebro se ven implicados en las emociones.

1. Córtex motor primario: Localizado en la circunvolución pre-central.

Las proyecciones axonales de las regiones motoras y somatoestésicas dan lugar a la vía piramidal, que proyecta directamente hacia los músculos a través de la vía corticoespinal. Regula la motricidad voluntaria, fundamentalmente a nivel distal y facial. Las áreas motoras primarias se relacionan con la coordinación y expresión del movimiento tanto grueso como fino.

2. Córtex premotor: Se ubica por delante del área primaria.

Proporciona la mayor cantidad de inputs asociados al córtex motor primario, constituyendo su área de asociación unimodal. Responde a las aferencias del procesamiento perceptivo visual.

3. Córtex motor suplementario:

Localizado a lo largo de las caras mediales de los hemisferios. Es un área de asociación plurimodal se activa antes de que comience un movimiento. Megías Cuenca, M. I. (2009). p. 127-128.

Las zonas mencionadas en el párrafo anterior son algunas de las partes implicadas del cerebro para que se genere un movimiento, aquí el lóbulo parietal son los de mayor activación al momento de formar una secuencia de movimientos no solo artísticos sino también en nuestras rutinas del día a día.

Por otro lado, en las emociones la parte principal que se ve implicada es el sistema límbico o cerebro límbico, los homínidos fueron evolucionando a medida que se les presentaban conflictos ya que, diversas teorías e investigaciones concuerdan que se tuvo un primer cerebro el cual se llamó el cerebro reptiliano, este se encarga de generar las conductas básicas de supervivencia como lo son el hambre, sueño, sexo con fines reproductivos, sed entre otras, luego se desarrolló el cerebro límbico; este nos permite generar empatía con el otro, supervivencia ante situaciones de miedo o peligro que conllevan a dar respuestas de huida, es aquí donde se relaciona al momento de darse una emoción, las emociones básicas se caracterizan por ser de alta intensidad y poco duración como es el caso de la alegría, miedo, asco, sorpresa y tristeza.

Estas emociones se combinan para poder generar sentimientos los cuales a diferencia de las emociones son de larga duración (tiempo) y corta intensidad, que a su vez segregan una serie de sustancias o neurotransmisores como por ejemplo dopamina, serotonina, glutamato, noradrenalina, gaba, etc. Por último, el homínido desarrollo un último cerebro que hasta la fecha se conoce como el neocórtex, este nos permite realizar funciones cognitivas más complejas al momento de resolver un problema o adquirir un nuevo conocimiento, además, este último nos diferencia de las otras especies de seres vivos. 
Otras de las estructuras cerebrales que conforman este circuito es el hipotálamo, que para Fustinoni, O. (2016). Regula parte de las funcione vegetativas, necesidades primarias o del cerebro reptiliano las cuales ya han sido descritas, la temperatura corporal y el sueño, al tiempo que ayuda a controlar la activación hormonal de la glándula pituitaria. Todos estos mecanismos tanto corporales como neurológicos son el resultado de la interacción con el ambiente y compaginar con otras teorías como la semiótica, dado que, como lo describe Zecchetto, V. (2002), la semiótica es una ciencia que depende de la realidad, resaltando en primera instancia la "realidad de la comunicación", es decir primero vivimos y practicamos la comunicación, y en segundo lugar se realiza una reflexión sobre su funcionamiento y estructura, es la interpretación de los signos y el significado que se le da.

Además, Zecchetto, V. (2002) describe la danza como; “libertad, movimiento, innovación, creación y expresividad, que a su vez involucra los signos como un lenguaje de expresión creativa conjugado con la plasticidad, fantasía y libre dinamismo". Dentro de este lenguaje de signos se encuentran reglas y códigos que forman un orden para integrarse. Es así como dentro del texto el autor rescata las características descritas por el lingüista ruso Román Jakobson, este importante investigador realizó un repertorio de seis funciones de los signos y el lenguaje según el modelo de comunicación que se esté manejando. Las funciones que plasmó el lingüista fueron:
a. El emisor (sus intenciones).
b. Los códigos y las formas.
c. El canal por el cual se trasmite el lenguaje.
d. El mensaje o contenido.
e. El referente u objetivo.
f. El preceptor junto con sus reacciones y efectos sobre el mensaje.

Las funciones que desempeñan los signos, el lenguaje y la comunicación se desenvuelven en diversos contextos, puesto que gracias a ellos y a la cultura nos permiten entender o comprender el lugar en donde se habita y esto permite la adaptación a un lugar, pero que al mismo tiempo sirve para entender otros significados que se les puede dar a aquello que se conoce, pero que puede ser interpretada de una manera distinta, dentro de este lenguaje de signos también se encuentra la publicidad, ya es por medio de esta que se generar un sinfín de significados de lo que ofrece la industria y el mercado a cada instante, cómo se mueve, qué transmite, por qué lo transmite de esa manera y cómo por medio de la innovación puede surgir un resultado mucho más satisfactorio al que se había tenido inicialmente.

Para Auladell, F. V. (2011). "El papel que ejerce la publicidad como ingrediente primordial de dicha producción semiótica, no consiste en anunciar o enunciar los productos de acuerdo con su realidad simbólica en la medida que corresponde a una determinada necesidad social, sino en llevar a cabo una función constructiva de las marcas, asignándoles una significación añadida que las clausure en un mundo imaginario que, además, permitirá dotarlas de un valor de consumo". p, 80 -81. Partiendo de las afirmaciones del autor la publicidad ha tratado de desarrollar una dimensión inmaterial de las marcas que buscan una lealtad; tratando de reemplazar la marca/función por la marca/emoción, es así como la actividad publicitaria se ha visto en la obligación de desarrollar nuevas estrategias que persigan el objetivo de mantener la ilusión referencial.

Es por ello que la danza se convierte en un mercado muy llamativo para el consumidor dado que el movimiento es el principal protagonista no solo a partir de lo que se observa sino también de lo que transmite y muestra como disciplina artística, código de identificación dentro de un contexto o cultura el cual lleva a diferenciarse entre la multitud y así tener un signo y un significado que se puede transformar al mismo tiempo que desarrolla habilidades físicas y cognitivas.

\section{Discusión y Conclusión}

En conclusión se describió cómo la danza fue tomando fuerza desde sus inicios, ya que esta viene ligada desde los primeros homínidos, pasando por los egipcios, culturas orientales, asiáticas y demás, que permitieron contribuir no solo a la danza sino a todos los ámbitos de conocimiento, puesto que, esta empezó a coger fuerza por medio del teatro debido a que en culturas desde el occidente al oriente y de norte a sur, tuvieron como primer escenario las calles para demostrar talentos y divertir a la gente el cual generaba una forma de 
ganar dinero y transmitir mensajes a quienes los observaban, esto fue pasando de voz a voz hasta llegar a los teatros, espacios diseñados para mostrar distintas formas del arte y es allí cuando la danza toma fuerza y admiración frente a quienes lo contemplaban y así verlo no solo por el lado del arte sino a su vez convertirla en algo mercantil y publicitario, en donde se pudiese encargar de mostrar desde diferentes formas esta rama del arte.

Sin embargo, se debido realizar diversas revisiones teóricas, análisis de pruebas, implementación de las mismas para lograr comprender qué motivaba a los individuos a generar estas conductas, con qué fin, qué partes a nivel fisiológico y neurológico implican tanto en la ejecución de los movimientos y expresiones corpóreas, como los procesos cognitivos y neuronales responsables de activar desde lo más reptiliano hasta los más desarrollado del sistema nervioso del ser humano conocido como corteza cerebral, que promueve ver la danza no solo como arte sino también como forma de consumo a través de los diversos anuncios publicitarios, por medio del estudio de los significados y los signos, donde se involucra el lenguaje, formas de comunicación entre otros.

El consumo de la danza se puede encontrar en los diferentes comerciales y anuncios publicitarios, que se perciben ya sea en los medios electrónicos y/o redes sociales, como en las pantallas de televisión; hoy en día es de mayor facilidad acceder a este tipo de información, donde la danza se hace protagonista al momento de exhibir un producto o servicio, ejemplo de ello son los comerciales realizados por marcas como Apple, Samsung, Ford, Nissan, carnavales, funciones de teatro, etc.

Como lo afirma Morand y Jaimovich (2018). "Nos interesa acceder a los procesos internos del cuerpo con el uso de nuevas tecnologías, y medirlos en tiempo real; que las cosas sucedan en vivo en escena. Desde ahí nace nuestro interés por el trabajo interactivo: transformar el cuerpo de los bailarines en cuerpos aumentados, híbridos, que están mapeados a video, que están mapeados a ambientes sonoros". Siguiendo esto la danza también genera conocimiento y aportes a otras líneas de aprendizaje.

\section{Referencias bibliográficas}

Auladell, F. V. (2011). La producción semiótica ante la significatización de la economía (O ¿cómo lograr una publicidad efectiva en la era del capitalismo virtual?). Pensar la publicidad, 5(1), 75-97.

Ávila, R. (2011). Enseñanzas artísticas y neurociencia de las emociones. Estudis escènics: quaderns de l'Institut del Teatre, (38), 425-436. Bosch, M. J. (2009). La danza de las emociones: Vives como sientes. Edaf.

Daza-Orozco, CE.; Cera-Ochoa, RA. (2018). Escritura con estilo: Guía práctica para publicar científicamente. Bogotá: Fundación Universitaria San Mateo. Recuperado de: http://palma.sanmateo.edu.co/index.php/catalogo/series/41-escritura-con-estilo-guiapractica-para-publicar-cientificamente

Daza-Orozco, CE., Cera-Ochoa, RA. (2018). La representación de las infancias en el cine de animación latinoamericano. Bogotá: Fundación Universitaria San Mateo.

Daza-Orozco, CE (2018). Narrativas visuales: perspectivas y análisis desde Iberoamérica. Bogotá: Fundación Universitaria San Mateo. Recuperado de: http://palma.sanmateo.edu.co/index.php/catalogo/colecciones/52-narrativas-visuales-perspectivas-y-analisisdesde-iberoamerica

Daza-Orozco, C. E. (2019). Historia de la infancia en el cine colombiano. Bogotá. Politécnico Grancolombiano. Recuperado de: http://alejandria.poligran.edu.co/handle/10823/1648

Daza-Orozco, C E. (2015). La metáfora cromática en el cine de infancia: una revisión a una década largometrajes sobre niñez. Revista Infancia Imágenes, 14(1), 59-76. https://doi.org/10.14483/udistrital.jour.infimg.2015.1.a05

Daza-Orozco, C E. (2015). Cartografía de los consumos y experiencias de la niñez en internet. Panorama, (11), 8 - 25. Recuperado a partir de https://revia.areandina.edu.co/index.php/Ll/article/view/438

De Balanzó, C., \& Sabaté, J. (2007). Neurociencias y publicidad: la nueva frontera de la persuasión. Les cruilles de la comunicació: límits i transgressions, IV Congrés Internacional de Comunicación y Realidad, Trípodos Extra, 2, 909-923.

De las Salas, M. L. (2015). Los procesos de formación en danza: una mirada a los procesos de enseñanza de la danza. Universidad del Atlántico.

Fustinoni, O. (2016). La música: química, emoción y cerebro. Química Viva, 15(1), 4-6.

Megías Cuenca, M. I. (2009). Optimización en procesos cognitivos y su repercusión en el aprendizaje de la danza.

Mora, A. S. (2011). El cuerpo en la danza desde la antropología (Doctoral dissertation, Facultad de Ciencias Naturales y Museo).

Morand, F., \& Jaimovich, J. (2018). Intersecciones frágiles: lenguaje inter (activo/diciplinar) danza y sonido. A. Dnz, 3(3), 160-163.

Mosterín, J. (2003). La insuficiencia de los paradigmas metafóricos en psicología. Revista de la Asociación Española de Neuropsiquiatría, (85), 89-104.

Norman-Acevedo, E. (2018). Rompiendo barreras: 10 Años de la Educación Virtual en el Politécnico Grancolombiano. Bogotá: Politécnico Grancolombiano.

Padilla, G. A. S. Teoría de la complejidad: Neurociencias y Biodanza.

Thompson, I. (2005). Definición de publicidad. Recuperado el, 6.

Zecchetto, V. (2002). La danza de los signos: nociones de semiótica general. 